\title{
Reúso de água residuária na produção de pimentão (Capsicum annuum L.)
}

\author{
José T. de Sousa ${ }^{1}$, Beatriz S. O. de Ceballos ${ }^{1}$, Israel N. Henrique ${ }^{1}$, José P. Dantas ${ }^{1} \&$ Suzana M. S. Lima ${ }^{1}$
}

\section{RESUMO}

Com o presente trabalho, objetivou-se avaliar o desempenho da cultura do pimentão (Capsicum annuum L.), submetida a cinco tratamentos distintos: 1) irrigação com água de poço e solo sem adubação; 2) irrigação com água de poço e solo com adubação mineral completa; 3) irrigação com água de poço e solo com adubação orgânica (vermicomposto); 4) irrigação com efluente de lagoa de polimento, e 5) irrigação com efluentes de reator UASB. O delineamento experimental foi de blocos casualizados, com quatro repetições, cujos dados foram submetidos à análise de variância e ao teste de Tukey. A cultura do pimentão com adubação orgânica apresentou a maior produtividade $(38,3 \mathrm{t} \mathrm{ha-1})$; outrossim, não houve diferença significativa em relação ao peso médio dos frutos e à área foliar, entre os tratamentos 2, 3 e 5, respectivamente, adubação mineral, adubação com vermicomposto e fertirrigação com efluente do reator UASB, mas a menor produtividade ocorreu com o tratamento 4, irrigado com efluente de lagoa de polimento.

Palavras-chave: reciclagem de nutrientes, agricultura no semi-árido, fertirrigação

\section{Wastewater reuse in the production of green pepper}

\begin{abstract}
In this paper an evaluation is made on the performance of cultivated green pepper submitted to five different treatments: 1) irrigation with well water and soil without fertilizer; 2) irrigation with well water and soil with mineral fertilization; 3) irrigation with well water and soil with organic fertilizer; 4) irrigation with polishing pond effluent; and 5) irrigation with UASB reactor effluent. The experiment was conducted in a randomized blocks design, with four repetitions, and data were submitted to variance analysis and Tukey test. The highest productivity of green pepper was observed when organic fertilizer was used $\left(38.3 \mathrm{tha}^{-1}\right)$. There were no significant differences between treatments 2,3 and 5 . The lowest productivity occured with treatment 4 irrigated with effluent of polishing pond.
\end{abstract}

Key words: nutrient recycling, semi-arid agriculture, fertirigation 


\section{INTRODUÇÃO}

O Nordeste brasileiro tem 58\% do seu território encravado na região semi-árida, caracterizada pela ocorrência do fenômeno das secas periódicas (Magalhães \& Campos, 1997). As chuvas se concentram, em geral, entre os meses de fevereiro a abril, ficando os nove meses restantes do ano, submetidos a um déficit hídrico que se acentua no decorrer do período, devido a elevados valores de temperatura e taxas de evapotranspiração, comprometendo os sistemas de cultivo de sequeiro, principal atividade econômica da região. Neste contexto, uma política adequada de gestão de recursos hídricos: captação de água durante o curto período chuvoso e armazenamento em poço profundo, barragens subterrâneas e reúso de águas residuárias, entre outras alternativas, poderão ser uma saída para a convivência com a estiagem.

A prática do reúso planejado de águas residuárias domésticas na agricultura, vem sendo apontada como excelente medida para atenuar o problema da escassez hídrica no semiárido, especificamente nas áreas circunvizinhas às cidades. Nas últimas décadas, é crescente a utilização de esgotos na agricultura, visto que se tem revelado como fonte natural de fertilizantes que garantem boa produtividade das culturas irrigadas. Contra isto, entretanto, pesam os aspectos sanitários dessas águas (Sousa \& Leite, 2003).

As águas residuárias domésticas, quando utilizadas sem tratamento adequado, podem contaminar o ambiente por concentrarem bactérias, parasitas e vírus que criam graves problemas de saúde pública, uma vez que propagam enfermidades de veiculação hídrica (Metcalf \& Eddy, 1991), que podem afetar não só os trabalhadores mas, também, os prováveis consumidores das culturas irrigadas incluindo-se, entre estes, os animais que se alimentam de pastagem irrigada com esgotos; portanto, o reúso de água residuária doméstica nessas condições, apresenta riscos potenciais à saúde pública (Shuval et al., 1986), razão pela qual os esgotos domésticos, antes de serem utilizados na agricultura, requerem tratamento prévio que, por sua vez, demanda a necessidade de se desenvolver tecnologias de baixo custo, para tal fim.

Em regiões de clima quente, como o Nordeste do Brasil, a utilização do reator UASB é uma opção positiva para o tratamento de esgotos domésticos. O efluente desse reator pode ser utilizado na agricultura, desde que aplicado em culturas como as do algodão e coqueiro, entre outras, consideradas categoria $\mathrm{C}$, que exigem poucos cuidados em relação a organismos patogênicos, de acordo com as recomendações da OMS (Organização Mundial da Saúde), para reúso (WHO, 1989). Os trabalhadores que manuseiam essas culturas, entretanto, correm riscos potenciais de serem contaminados por parasitas.

A qualidade sanitária de um efluente depende do grau de tratamento efetuado e da exigência para seu uso. A segurança poderá ser obtida a partir de um pós-tratamento do efluente. A utilização de Lagoas de Estabilização é o melhor método de tratamento terciário para esgoto sanitário, quando se objetiva produzir efluentes com padrões ade- quados para uso irrestrito na agricultura (WHO, 1989). A configuração e a geometria desses sistemas e o elevado tempo de detenção hidráulica, permitem a ação bactericida dos fatores ambientais adversos ao crescimento dos microrganismos presentes, responsáveis pela produção de efluentes de boa qualidade para a irrigação irrestrita, com base nos principais indicadores da Organização Mundial de Saúde: coliformes termotolerantes e ovos de helmintos (Cavalcanti, 2003).

Os aspectos conceituais dos projetos de construção e operacionalização de lagoas de estabilização aeróbia, anaeróbia, facultativa e lagoa de polimento, são amplamente discutidos pela literatura especializada (Silva \& Mara, 1979; van Haandel \& Lettinga, 1994; Kellner \& Pires, 1998; von Sperling, 2002; Cavalcanti, 2003).

O efluente do reator anaeróbio de manta de lodo, designado também por reator UASB (up flow anaerobic sludge blanket) apresenta baixa concentração de material orgânico; conseqüentemente, baixa turbidez; logo, quando submetido a pós-tratamento em lagoa de polimento, produzirá reduzida quantidade de $\mathrm{CO}_{2}$; além deste fato, nos trópicos a alta insolação sobre a superfície da água acumulada na lagoa promove intensa atividade fotossintética, aumentando o consumo de gás carbônico, que eleva o pH no meio, favorecendo o decaimento de bactérias patogênicas e indicadoras (Cavalcanti et al., 2000; van Haandel \& Lettinga, 1994). Este aumento de pH é fundamental para a higienização do efluente, mas promove, concomitantemente, a redução de nutrientes. Valores de $\mathrm{pH}$ acima de 9,0 unidades proporcionam, no meio líquido, o desequilíbrio das espécies de fosfato, resultando na precipitação de fósforo, geralmente nas formas de fosfato de cálcio e hidroxiapatita; já o nitrogênio amoniacal, também encontrado no meio, pode ser removido na forma de gás amônio, por processos físicos de dessorção, além de absorção na biomassa fitoplantônica, em rápido crescimento (Cavalcanti et al., 2000).

A remoção de nutrientes é fundamental para atenuar o processo de eutrofização, entre outros impactos ambientais, quando as águas superficiais são o destino final do efluente porém, quando o efluente se destina à irrigação, o interesse é manter altas concentrações de fósforo e de nitrogênio, uma vez que esses elementos substituirão os fertilizantes químicos; portanto, o efluente da lagoa de polimento apresenta boa qualidade sanitária, podendo ser utilizado para a irrigação irrestrita, muito embora possua baixa quantidade de nutrientes e elevado $\mathrm{pH}$, fator que, provavelmente, poderá tornálo pouco adequado para a utilização em culturas sensíveis a águas alcalinas.

O trabalho foi realizado com o objetivo de verificar o desempenho da cultura irrigada do pimentão (Capsicum annuum L.), com efluentes de lagoa de polimento e efluente de reator UASB, e comparar o desempenho dessa mesma cultura com o dos seguintes tratamentos: irrigação com água de poço e solo com adubação mineral completa (macro e micronutrientes), irrigação com água de poço e solo adubado com vermicomposto e irrigação com água de poço e solo sem adubação. 


\section{MATERIAL E MÉTODOS}

O experimento foi conduzido em solo classificado como Podzólico Vermelho Amarelo Eutrófico, numa área de agricultura familiar localizada no município de Lagoa Seca, PB, realizado em parceria com o Sindicato dos Trabalhadores Rurais daquele município. A cidade de Lagoa Seca está situada entre as coordenadas geográficas de $7^{\circ} 15^{\prime} 18$ ”' de latitude Sul e $35^{\circ} 52^{\prime}$ '28” de longitude Oeste, com altitude de $550 \mathrm{~m}$.

Anterior ao preparo das parcelas, foram coletadas 10 amostras simples de solo sendo que, para cada parcela, gerou-se uma amostra composta, totalizando 20 amostras, as quais foram analisadas para determinação de: matéria orgânica, nitrogênio, fósforo, potássio, cálcio, magnésio, enxofre, boro, cloro, cobre, ferro, manganês, zinco, sódio, alumínio, hidrogênio alumínio e pH; realizaram-se, também, análises para salinidade, $\mathrm{pH}$, cálcio, magnésio, sódio, potássio, carbonato, bicarbonato, cloreto, sulfato e condutividade elétrica no extrato de saturação do solo, seguindo-se a metodologia recomendada por Tedesco et. al. (1995).

As características físico-hídricas do solo, determinadas no Laboratório de Salinidade da UFCG, conforme metodologia da EMBRAPA (1979) estão apresentadas na Tabela 1, na qual se observa que o solo possui textura arenosa, mas baixos valores de condutividade elétrica.

Utilizando-se um regador, aplicou-se a água em sistema de sulco. Conforme os dados oriundos da análise físico-hídrica do solo (Tabela 1), a quantidade de água necessária para a cultura do pimentão, calculada até a profundidade de $0,50 \mathrm{~cm}$, foi de $6 \mathrm{~L} \mathrm{~m}^{-2} \mathrm{~d}^{-1}$.

O delineamento experimental foi o de blocos casualizados, com cinco tratamentos e quatro repetições, totalizando

Tabela 1. Características físico-hidricas do solo utilizado no experimento

\begin{tabular}{cccccc}
\hline Características & \multicolumn{5}{c}{ Tratamentos } \\
fisico-hídricas do solo & T1 & T2 & T3 & T4 & T5 \\
\cline { 2 - 6 } Granulometria $\left(\mathrm{g} \mathrm{kg}^{-1}\right)$ & & & & & \\
Areia & 709,2 & 707,5 & 701,2 & 703,1 & 709,2 \\
\hline Siltre & 131,5 & 130,2 & 131,8 & 129,3 & 130,5 \\
Argila & 159,3 & 156,8 & 154,1 & 158,8 & 157,5 \\
\hline Classificação textural & Franco & Franco & Franco & Franco & Franco \\
& arenoso & arenoso & arenoso & arenoso & arenoso \\
Densidade aparente $\left(\mathrm{g} \mathrm{cm}^{-3}\right)$ & 1,41 & 1,42 & 1,40 & 1,41 & 1,41 \\
\hline Densidade real $\left.(\mathrm{g} \mathrm{cm})^{-3}\right)$ & 2,60 & 2,60 & 2,60 & 2,60 & 2,60 \\
\hline Porosidade (\%) & 45,79 & 45,86 & 45,96 & 45,74 & 45,76 \\
\hline Unidade (\%) & - & - & - & - & - \\
\hline Natural & 1,11 & 1,11 & 1,11 & 1,11 & 1,11 \\
\hline 0,33 atm & 14,09 & 14,99 & 14,90 & 14,89 & 14,69 \\
\hline Equivalente & - & - & - & - & - \\
\hline 15 atm & 5,30 & 5,35 & 5,35 & 5,35 & 5,35 \\
\hline Água disponível & 8,79 & 9,64 & 9,64 & 9,64 & 9,64 \\
\hline
\end{tabular}

T1- irrigação com água de poço artesiano; T2 - irrigação com água de poço artesiano, sendo o solo adubado com fertilizantes minerais; T3 - irrigação com água de poço, com 0 solo adubado com vermicomposto; T4 - irrigação com efluente de lagoa de polimento; T5 - irrigação com efluente de reator UASB
Tabela 2. Teor de nutrientes existentes $\left(\mathrm{mg} \mathrm{dm}^{-3}\right)$ e quantidade adicionada ao solo do tratamento 2, expressos em $\mathrm{kg} \mathrm{ha}^{-1}$

\begin{tabular}{cccc}
\hline $\begin{array}{c}\text { Nutriente } \\
\left(\mathbf{m g ~ d m}^{-3}\right)\end{array}$ & $\begin{array}{c}\text { Nutriente } \\
\text { existente no solo } \\
\left(\mathbf{m g ~ d m}^{-3}\right)\end{array}$ & $\begin{array}{c}\text { Nutriente } \\
\text { adicionado } \\
\left(\mathbf{m g ~ d m}^{-3}\right)\end{array}$ & $\begin{array}{c}\text { Nutriente } \\
\text { adicionado } \\
\left(\mathbf{k g ~ h a}^{-1}\right)\end{array}$ \\
\hline Nitrogênio & 200 & - & - \\
\hline Fósforo & 125 & 75 & 150 \\
\hline Potássio & 132,6 & 67,4 & 134,8 \\
Cálcio & 840 & - & - \\
\hline Magnésio & 279,4 & - & - \\
\hline Enxofre & 14 & 36 & 0,70 \\
\hline Boro & 0,65 & 0,35 & 1,596 \\
\hline Cobre & 0,3 & 1,7 & 3,4 \\
\hline Ferro & 53 & - & - \\
\hline Manganês & 3,1 & - & - \\
\hline Zinco & 2,0 & - & - \\
\hline
\end{tabular}

(-) não houve aplicação do nutriente, ao solo uma vez que já havia em quantidade suficiente

20 parcelas experimentais, que foram preparadas medindo $1 \mathrm{~m}$ de largura por 1,5 m de comprimento cada uma, com parcela de 1,5 $\mathrm{m}^{2}$ de área, separadas cerca de $6 \mathrm{~m}$.

A adubação efetuada no T2 seguiu recomendação de Malavolta (1965) conforme Tabela 2; já para a adubação orgânica (T3) aplicou-se o quantitativo de $50 \mathrm{t} \mathrm{ha}^{-1}$ de vermicomposto, cujas características estão apresentadas na Tabela 3.

Preparadas as parcelas e feitas as adubações mineral e orgânica, conforme os tratamentos empregados, efetuou-se o transplante das mudas de pimentão (Capsicum annuum L.) previamente produzidas em sementeira. Entre as mudas, o espaçamento foi de 0,40 x 0,40 m, correspondendo a 12 plantas por parcela. A partir do transplante, as irrigações foram realizadas de acordo com o tratamento, sendo as águas de poço e as residuárias submetidas a análises físico-química, microbiológica e parasitológica.

Transcorridas duas semanas após o transplante das mudas, determinou-se a massa seca (MS) por planta, através do processo de secagem em estufa com circulação de ar forçada, até se obter o peso constante, a temperatura de $65 \pm 0,5^{\circ} \mathrm{C}$.

A área foliar (AF) foi determinada através da utilização de um furador cilíndrico de área conhecida, retirando-se discos foliares. Os discos eram levados à estufa e depois pesados para a determinação da área foliar total da planta. A produção da matéria seca obtida por tratamento e repetição foi submetida a análise de variância, comparando-se as médias entre os tratamentos pelo teste Tukey a $5 \%$.

A quantificação dos microrganismos indicadores de contaminação fecal foi realizada segundo o APHA (1995). A enumeração, a identificação e a análise da viabilidade de ovos de helmintos, seguiram a metodologia recomendada por Bailenger (1989), modificada. Para a determinação de coliformes no fruto do Pimentão, seguiu-se a seguinte metodologia: tomaram-se aleatoriamente, 5 pimentões por parcela; cada fruto foi previamente pesado e colocados em saco plástico estéril com zíper (marca Sanremo de 27 x $31 \mathrm{~cm}$ ). Adicionou-se o volume do líquido de diluição (solução salina de 
Tabela 3. Características dos constituintes do vermicomposto utilizado no solo do tratamento 3

\begin{tabular}{|c|c|c|}
\hline Parâmetro & $\begin{array}{l}\text { Concentração em } \\
\text { umidade natural }\end{array}$ & $\begin{array}{l}\text { Concentração } \\
\text { em base seca }\end{array}$ \\
\hline $\mathrm{pH}$ & 7,1 & - \\
\hline Densidade $\left(\mathrm{g} \mathrm{cm}^{-3}\right)$ & 0,88 & - \\
\hline Umidade perdida a $60-65^{\circ} \mathrm{C}(\%)$ & 5,47 & - \\
\hline Umidade perdida entre 65 e $110^{\circ} \mathrm{C}(\%)$ & 2,28 & - \\
\hline Umidade total & 7,75 & 0,0 \\
\hline Inertes & 0,0 & - \\
\hline Matéria orgânica total (combustão) (\%) & 21,57 & 23,38 \\
\hline Matéria orgânica compóstavel (\%) & 15,80 & 17,13 \\
\hline $\begin{array}{l}\text { Matéria orgânica resistente a } \\
\text { compostagem (\%) }\end{array}$ & 5,77 & 6,25 \\
\hline Carbono total (orgânico e mineral) (\%) & 11,98 & 12,99 \\
\hline Carbono orgânico (\%) & 8,78 & 9,852 \\
\hline Resíduo mineral total (\%) & 70,68 & 76,62 \\
\hline Resíduo mineral insolúvel (\%) & 61,53 & 66,70 \\
\hline Resíduo mineral solúvel (\%) & 9,15 & 9,92 \\
\hline Nitrogênio total (\%) & 0,99 & 1,07 \\
\hline Fósforo total (\%) & 1,67 & 1,81 \\
\hline Potássio total (\%) & 0,40 & 0,43 \\
\hline Cálcio total (\%) & 2,11 & 2,29 \\
\hline Magnésio total (\%) & 0,56 & 0,61 \\
\hline Enxofre total (\%) & 0,12 & 0,13 \\
\hline Relação C/N (C total e $\mathrm{N}$ total) & $12 / 1$ & $12 / 1$ \\
\hline Relação C/N (C orgânico e N total) & $9 / 1$ & $9 / 1$ \\
\hline Cobre total $\left(\mathrm{mg} \mathrm{kg}^{-1}\right)$ & 19 & 21 \\
\hline Manganês total $\left(\mathrm{mg} \mathrm{kg}^{-1}\right)$ & 342 & 371 \\
\hline Zinco total $\left(\mathrm{mg} \mathrm{kg}^{-1}\right)$ & 80 & 80 \\
\hline Ferro total $\left(\mathrm{mg} \mathrm{kg}^{-1}\right)$ & 6938 & 7521 \\
\hline Boro $\left(\mathrm{mg} \mathrm{kg}^{-1}\right)$ & 25 & 27 \\
\hline Sódio total $\left(\mathrm{mg} \mathrm{kg}^{-1}\right)$ & 543 & 543 \\
\hline
\end{tabular}

cloreto de magnésio e fosfato de potássio monobásico, $\mathrm{pH}$ 7,2), na proporção de $10 \mathrm{~mL}$ de líquido de diluição para 1 g de pimentão; esta solução se constituiu na primeira diluição $\left(10^{-1}\right)$. Com o zíper fechado durante $5 \mathrm{mim}$, foram massageadas de forma que o diluente ficasse em contato com todas as amostras seguidamente, procedeu-se à preparação das diluições seriadas $\left(10^{-2}\right.$ a $\left.10^{-5}\right)$.

\section{RESULTADOS E DISCUSSÃO}

\section{Características químicas e fertilidade do solo}

A Tabela 4 apresenta os valores dos resultados da caracterização química do solo e o resumo da análise de variância entre as médias das variáveis de fertilidade do solo antes e após do término do experimento. A segunda análise de solo mostrou que com exceção do fósforo assimilável, os demais nutrientes aumentaram no solo durante o período do ciclo da cultura. Observa-se, ainda, que os valores relativos a salinidade e sodicidade em todos os tratamentos, estão dentro da normalidade (Ayers \& Westcot ,1991).
Tabela 4. Características químicas do solo após o término do experimento

\begin{tabular}{|c|c|c|c|c|c|}
\hline \multirow{2}{*}{$\begin{array}{l}\text { Características químicas } \\
\text { (fertilidade do solo) }\end{array}$} & \multicolumn{5}{|c|}{ Tratamento } \\
\hline & T1 & T2 & T3 & T4 & T5 \\
\hline $\mathrm{pH}$ & 7,15 & 6,75 & 7,09 & 7,20 & 7,00 \\
\hline Cálcio $\left(\mathrm{cmol}_{\mathrm{c}} \mathrm{dm}^{-3}\right)$ & $5,1^{\text {s.n }}$ & $9,4^{*}$ & $7,30^{*}$ & $5,5^{\text {s.n }}$ & $5,33^{\text {s.n }}$ \\
\hline Magnésio $\left(\mathrm{cmol}_{\mathrm{c}} \mathrm{dm}^{-3}\right)$ & $3,5^{\text {s.n }}$ & $2,70^{\text {s.n }}$ & $5,20 *$ & $4,5^{*}$ & $3,56^{\text {s.n }}$ \\
\hline Sódio $\left(\mathrm{cmol}_{\mathrm{c}} \mathrm{dm}^{-3}\right)$ & $0,6^{*}$ & $0,63^{*}$ & $0,69 *$ & $0,69 *$ & $0,58^{*}$ \\
\hline Potássio $\left(\mathrm{cmol}_{\mathrm{c}} \mathrm{dm}^{-3}\right)$ & $0,19^{\text {s.n }}$ & $0,25^{\mathrm{s.n}}$ & $0,30^{\text {s.n }}$ & $0,34^{\mathrm{s.n}}$ & $0,25^{\text {s.n }}$ \\
\hline Soma da base $\left(\mathrm{cmol}_{\mathrm{c}} \mathrm{dm}^{-3}\right)$ & $9,39 *$ & $12,98^{*}$ & $13,49 *$ & $11,03^{*}$ & $9,72^{*}$ \\
\hline Hidrogênio $\left(\mathrm{cmol}_{\mathrm{c}} \mathrm{dm}^{-3}\right)$ & 0,00 & $0,82^{*}$ & 0,00 & 0,00 & $0,16^{*}$ \\
\hline Alumínio $\left(\mathrm{cmol}_{\mathrm{c}} \mathrm{dm}^{-3}\right)$ & 0,00 & 0,00 & 0,00 & 0,00 & 0,00 \\
\hline CTC $\left(\mathrm{cmol}_{\mathrm{c}} \mathrm{dm}^{-3}\right)$ & $9,02^{\text {s.n }}$ & $13,58^{*}$ & $13,49 *$ & $11,17^{*}$ & $9,88^{\text {s.n }}$ \\
\hline Carbono orgânico $\left(\mathrm{g} \mathrm{kg}^{-1}\right)$ & $13,10^{\text {s.n }}$ & $13,3^{s . n}$ & $22,25^{*}$ & $11,17^{\mathrm{s} \cdot \mathrm{n}}$ & $28,35^{*}$ \\
\hline Material Orgânico $\left(\mathrm{g} \mathrm{kg}^{-1}\right)$ & $5,7^{\text {s.n }}$ & $22,40^{\star}$ & $41,10^{\star}$ & $19,5^{s . n}$ & $32,25^{*}$ \\
\hline Fósforo assimilável ( $\left.\mathrm{g} \mathrm{kg}^{-1}\right)$ & $0,125^{\text {s.n }}$ & $0,125^{s . n}$ & $0,125^{s . n}$ & $0,125^{s . n}$ & $0,125^{\mathrm{s.n}}$ \\
\hline $\begin{array}{l}\mathrm{CE}\left(\mathrm{dS} \mathrm{m}^{-1}\right) \\
\text { Suspensão solo-água }\end{array}$ & $0,21^{\text {s.n }}$ & 0,26 & $0,28^{s . n}$ & $0,25^{s . n}$ & $0,20^{\text {s.n }}$ \\
\hline
\end{tabular}

s.n - Não significativo; * Significativo a $5 \%$ pelo teste Tukey

A ausência de alumínio $\left(\mathrm{Al}^{+3}\right)$ trocável e o $\mathrm{pH}$ próximo da neutralidade caracterizam um solo próprio para a maioria das culturas, mas os teores de sódio aumentaram em todos os tratamentos, verificando-se diferença significativa entre a média das concentrações, antes e depois do experimento. O sódio presente na água de irrigação favorece a elevação da porcentagem de sódio trocável (PST) no solo, afetando suas propriedades físicas e químicas e dificultando a atividade da água a ser utilizada pela planta (Holanda \& Amorim, 1997). Também foi significativo $(\mathrm{p}<0,05)$ para o cálcio, apenas nos tratamentos T2 e T3, adubação mineral completa e vermicomposto, respectivamente.

Quanto à matéria orgânica, constataram-se valores significativos nos tratamentos T3 (vermicomposto) e T5 (efluente do reator UASB). A matéria orgânica é fonte de energia para os microrganismos, de forma que a bioestrutura granular aumenta a capacidade de armazenar umidade, reter e fixar fósforo e nitrogênio, aumentar a capacidade de troca de cátions (CTC), ajudar a segurar potássio, cálcio e magnésio, entre outros nutrientes disponíveis para as raízes da planta (Primavesi, 2002). A condutividade elétrica da suspensão solo água, aumentou em todos os tratamentos, porém não se verificou diferença significativa entre as médias da condutividade antes nem depois do experimento. Os resultados da Tabela 4 mostram que o valor da condutividade elétrica variou de 0,20 a $0,28 \mathrm{dS} \mathrm{m}^{-1}$. Na classificação de solos afetados por sais, esses valores são relativamente baixos (Queiroz et al., 1997).

\section{Características do esgoto e das águas de irrigação}

A Tabela 5 apresenta as principais características dos efluentes utilizados na irrigação da cultura do pimentão e nela se verifica que a concentração de nitrogênio e fósforo no efluente de lagoa é bem inferior quando comparada com o efluente do reator UASB.

Com relação à concentração de coliformes termotolerantes 
e ovos de helmintos, o efluente da lagoa de polimento obedece às exigências da WHO (1989); no entanto, apresenta uma quantidade abundante de algas mantendo, assim, considerável concentração de sólidos suspensos (84 mg L $\left.\mathrm{L}^{-1}\right)$. Efluentes com tal característica podem obstruir os sistemas de irrigação mas, sendo esses efluentes utilizados em sistemas de irrigação por sulco, as algas, enquanto matéria orgânica que lentamente se decompõe e humifica o solo, contribuirão com nutrientes, sobretudo nitrogênio e fósforo.

Outra característica observada no efluente da lagoa é o valor elevado do seu pH, em média 9,0, o que pode ser obstáculo para a irrigação de diversas culturas. Considera-se adequado para água de irrigação um pH entre 6,5 e 8,4; fora dessa faixa, favorece o desequilíbrio nutricional das culturas irrigadas (Ayers \& Westcot, 1991).

Verifica-se, ainda na Tabela 5, alta concentração de cloreto (169 mg L-1) e sódio (120 $\mathrm{mg} \mathrm{L}^{-1}$ ) na água de poço, favorecendo uma condutividade elétrica considerável (1,0 dS m-1), que se torna ainda mais elevada nos efluentes do reator UASB $\left(1,5 \mathrm{dS} \mathrm{m}^{-1}\right)$ e lagoa de polimento $\left(1,6 \mathrm{dS} \mathrm{m}^{-1}\right)$; esta constatação deixa claro que a fertirrigação com efluentes de esgotos domésticos pode trazer efeitos deletérios para o crescimento das plantas, em virtude do aumento dos sais, caso não se tenha um manejo adequado de irrigação e drenagem.

\section{Presença de microrganismos no solo e no fruto}

Organismos patogênicos presentes nos esgotos não penetram no tecido vegetal, a não ser que a planta esteja danificada, mas alguns patógenos podem ser encontrados na superfície das plantas fertirrigadas com esgotos tratados. De modo geral, sua sobrevivência depende de fatores como luz solar, temperatura e umidade relativa do ar, entre outros. Neste caso, os microrganismos presentes na superfície das culturas estão expostos às condições ambientais desfavoráveis.

Os dados apresentados nas Tabelas 6 e 7 demonstram que a concentração de coliformes termotolerantes e Escherichia. coli é maior no solo, após a colheita, que nos frutos. A sobrevivência de bactérias entéricas no solo depende também da atividade autogênica de actinomicetos e fungos, os quais produzem antibióticos que as eliminam; por outro lado, a sobrevivência dessas bactérias pode ser prolongada em solos com nutrientes disponíveis (Paganini, 2003).

Diversos pesquisadores, estudando o período de sobrevivência de microrganismos em hortaliças, constataram que $E$. coli e Salmonella spp sobrevivem até dez dias, após a última irrigação (Paganini, 2003).

As análises microbiológicas demonstraram que coliformes termotolerantes e $E$. coli presentes no efluente e no solo, contaminaram os frutos do pimentão irrigado, mas em níveis aceitáveis para o consumo. Os métodos de irrigação contribuem, sobremaneira, para a contaminação dos produtos; aconselha-se, neste caso, a irrigação subsuperficial e localizada, uma vez que, mesmo havendo a possibilidade de risco de contato direto dos trabalhadores com o efluente, este sistema é o de menor risco de contaminação.

A Legislação Brasileira para Padrões Microbiológicos de Hortaliças, estabelece um número mínimo de cinco "unidades amostrais”, das quais duas podem apresentar densidade
Tabela 5. Valores médios $(\overline{\boldsymbol{X}})$ desvio padrão $(\delta)$ de trinta determinações de esgotos brutos e tratados (temperatura de 25 a $30{ }^{\circ} \mathrm{C}$ ) para reúso na agricultura

\begin{tabular}{|c|c|c|c|c|}
\hline \multirow{2}{*}{ Parâmetro } & \multirow{2}{*}{$\begin{array}{c}\text { Esgoto bruto } \\
\qquad \bar{x}\end{array}$} & UASB & $\begin{array}{l}\text { Lagoa de } \\
\text { polimento }\end{array}$ & $\begin{array}{l}\text { Água de } \\
\text { poço }\end{array}$ \\
\hline & & $\bar{x}$ & $\bar{x}$ & $\delta \quad \bar{x} \delta$ \\
\hline $\mathrm{DQO}\left(\mathrm{mg} \mathrm{L}^{-1}\right)$ & $400 \pm 14$ & $150 \pm 30$ & $235 \pm 50$ & $50 \pm 20$ \\
\hline 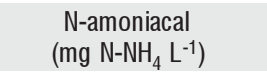 & $0 \pm 17$ & $55 \pm 8$ & $7,5 \pm 2$ & - \\
\hline NT K (mg NTK L-1) & $72 \pm 14$ & $58 \pm 30$ & $14,4 \pm 8$ & $1,5 \pm 0,09$ \\
\hline Fósforo Total (mg P L-1) & $7,5 \pm 2$ & $6,4 \pm 2$ & $4,0 \pm 1$ & $0,2 \pm 0,04$ \\
\hline Potássio (mg K L-1) & $35 \pm 2$ & $35 \pm 3$ & $40 \pm 1,3$ & $8,5 \pm 1,4$ \\
\hline SS $\left(\mathrm{mg} \mathrm{L}^{-1}\right)$ & $140 \pm 18$ & $23 \pm 13$ & $84 \pm 11$ & - \\
\hline Cálcio (mg L-1) & $42 \pm 7,8$ & $43 \pm 6,1$ & $44 \pm 8,1$ & $24 \pm 9,1$ \\
\hline Magnésio (mg L-1) & $15 \pm 4,0$ & $20 \pm 5,1$ & $19 \pm 5,4$ & $19 \pm 6,0$ \\
\hline Cobre $\left(\mathrm{mg} \mathrm{L}^{-1}\right)^{*}$ & 0,02 & 0,02 & $<0,02$ & $<0,02$ \\
\hline Zinco $\left(\mathrm{mg} \mathrm{L}^{-1}\right)^{*}$ & 0,04 & 0,06 & 0,02 & 0,02 \\
\hline Ferro $\left(\mathrm{mg} \mathrm{L}^{-1}\right)^{*}$ & 3,3 & 1,5 & 0,13 & 1,9 \\
\hline Manganês $\left(\mathrm{mg} \mathrm{L}^{-1}\right)^{\star}$ & 0,16 & 0,06 & 0,04 & 0,25 \\
\hline Sódio $\left(\mathrm{mg} \mathrm{L}^{-1}\right)$ & $152 \pm 24$ & $130 \pm 21$ & $144 \pm 18$ & $120 \pm 35$ \\
\hline Boro $\left(\mathrm{mg} \mathrm{L}^{-1}\right)^{\star}$ & 0,12 & 0,14 & 0,17 & 0,15 \\
\hline Molibidênio (mg L-1)* & $<1$ & $<1$ & $<1$ & $<1$ \\
\hline Níquel $\left(m g L^{-1}\right)^{*}$ & 0,02 & 0,02 & $<0,02$ & $<0,02$ \\
\hline Sulfato (mg L-1) & $31 \pm 12$ & $1,4 \pm 0,2$ & $42 \pm 10$ & $1,7 \pm 0,20$ \\
\hline Cloreto $\left(\mathrm{mg} \mathrm{L}^{-1}\right)$ & $171 \pm 21$ & $190 \pm 18$ & $218 \pm 19$ & $169 \pm 29$ \\
\hline $\begin{array}{l}\text { Ovos de helmintos } \\
\quad \text { (ovos } \mathrm{L}^{-1} \text { ) }\end{array}$ & $150 \pm 90$ & $50 \pm 15$ & nd & $\mathrm{Nd}$ \\
\hline Condutividade (dS m $\mathrm{m}^{-1}$ ) & $1,50 \pm 0,2$ & $1,5 \pm 0,1$ & $1,60 \pm 0,1$ & $1,00 \pm 0,01$ \\
\hline $\begin{array}{l}\text { Coliformes } \\
\text { termotolerantes } \\
\text { (UFC } 100 \mathrm{~mL}^{-1} \text { ) }\end{array}$ & $8,50 \times 10^{6}$ & $4,0 \times 10^{5}$ & $2,0 \times 10^{2}$ & $1 \times 10^{2}$ \\
\hline $\mathrm{pH}$ & $7,0-7,3$ & $7,1-7,6$ & $8,5-9,8$ & $7,3-7,5$ \\
\hline
\end{tabular}

* Amostras sem repetições, analisadas no departamento de solo da UFRGS, em 2002

de coliformes termotolerantes, até o valor máximo de $10^{2}$ org g $^{-1}$, em qualquer unidade do lote (ANVISA, 2001); portanto, do ponto de vista do indicador de contaminação fecal o pimentão produzido no experimento, conforme os dados da Tabela 6, apresenta qualidade sanitária aceitável para serem consumidos apenas os frutos produzidos no tratamento 4, irrigados com efluentes da lagoa de polimento. Os critérios para a irrigação irrestrita apresentados pela Organização Mundial de Saúde (WHO, 1989) são rígidos, quando se trata da remoção de ovos de helmintos, mas não faz referência a cistos de protozoários e vírus.

Do ponto de vista epidemiológico, Shuval et al. (1997) fizeram uma avaliação de risco para a população de Israel, que comia 100 g de pepino por dia, oriundos de culturas irrigadas

Tabela 6. Microrganismos presentes no fruto do pimentão, expressos em NMP g-1

\begin{tabular}{cccccc}
\hline \multirow{2}{*}{ Organismos } & \multicolumn{5}{c}{ Tratamentos } \\
\cline { 2 - 6 } & T1 & T2 & T3 & T4 & T5 \\
Coliformes & $4,6 \times 10^{2}$ & $1,6 \times 10^{2}$ & $1,1 \times 10^{2}$ & $10^{1}$ & $2,4 \times 10^{3}$ \\
termotolerantes (NMP g) & & & & & \\
Escherichia coli (NMP g) & $<2,2$ & $<2,2$ & 4,0 & 3,0 & 10 \\
\hline
\end{tabular}


Tabela 7. Microrganismos presentes no solo após a colheita dos frutos, NMP g-1

\begin{tabular}{cccccc}
\hline \multirow{2}{*}{ Organismos } & \multicolumn{5}{c}{ Tratamentos } \\
\cline { 2 - 6 } & T1 & T2 & T3 & T4 & T5 \\
Coliformes & $4,7 \times 10^{4}$ & $4,6 \times 10^{4}$ & $1,1 \times 10^{5}$ & $2,9 \times 10^{3}$ & $1,0 \times 10^{6}$ \\
termotolerantes (NMP g) & $1 \times 10^{2}$ & $1 \times 10^{2}$ & $5 \times 10^{4}$ & $4,6 \times 10^{2}$ & $2,7 \times 10^{3}$ \\
\hline Escherichia coli (NMP g) & $1 \times 10^{2}$
\end{tabular}

com efluentes tratados, contendo cerca de $1000 \mathrm{UFC} / 100 \mathrm{~mL}$, em conformidade com a WHO (1989), e constataram que o risco anual de contrair uma doença por vírus é aproximadamente de $10^{-6}$ a $10^{-7}$ (ocorrência de uma infecção a cada 1.000 .000 a 10.000 .000 ano), enquanto por infecção por rotavirus, é da ordem de $10^{-5}$ a $10^{-6}$. Neste contexto e se considerando o modelo de Shuval et al. (1997), tem-se que o pimentão produzido no experimento apresenta nível muito baixo de risco para a difusão de doenças.

\section{Análise de crescimento da cultura do pimentão}

De acordo com a Figura 1, as plantas que apresentaram maior crescimento, $63,5 \mathrm{~cm}$ em média, foram aquelas submetidas ao tratamento 3; já as plantas submetidas ao tratamento 5 , apresentaram desenvolvimento médio ligeiramente inferior, alcançando a altura de 60,4 cm. Com os tratamentos 2, 4 e 1, o crescimento médio foi, respectivamente, de 55,9, 54,8 e 47,4 cm. Estatisticamente, não se constatou diferença significativa entre os cinco tratamentos.

Na Tabela 8 apresentam-se os valores médios do diâmetro, do número de frutos, do peso médio por tratamento, da área foliar das plantas de pimentão e a produção por unidade de área.

A Figura 2 apresenta o desenvolvimento da área foliar em todos os tratamentos. Nota-se, no tratamento 3 , que a área foliar foi maior durante o período vegetativo, em virtude das condições favoráveis de água e nutrientes disponibilizados para a planta; no tratamento 5 (efluente do reator UASB), a área foliar da cultura atingiu valor próximo ao obtido com o tratamento por adubação mineral, o que pode ser considerado bom desempenho.

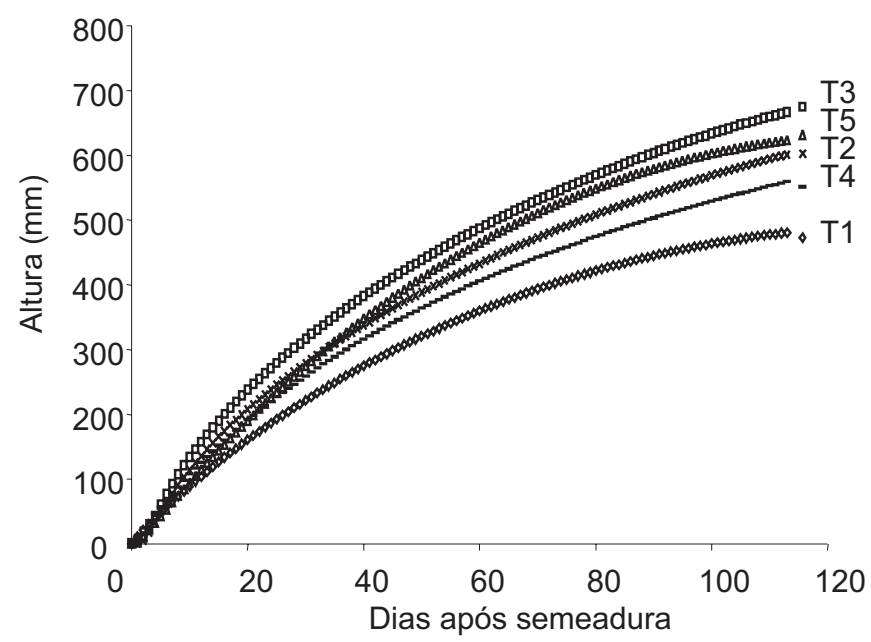

Figura 1. Altura do pimentão após a semeadura
Tabela 8. Características vegetativas das plantas de pimentão segundo 0 tratamento a que foram submetidas

\begin{tabular}{|c|c|c|c|c|c|}
\hline Tratamento & $\begin{array}{l}\text { Diâmetro da } \\
\text { planta }(\mathrm{mm})\end{array}$ & $\begin{array}{l}\mathrm{N}^{0} \text { de Frutos } \\
\text { por parcela }\end{array}$ & $\begin{array}{l}\text { Peso médio } \\
\text { dos frutos }(\mathrm{g})\end{array}$ & $\begin{array}{l}\text { Área foliar } \\
\text { (cm²) }\end{array}$ & $\begin{array}{l}\text { Produtividade } \\
\left(\mathrm{t} \mathrm{ha}^{-1}\right)\end{array}$ \\
\hline $\mathrm{T} 1$ & $12,87 \mathrm{~b}$ & $42,75 \mathrm{~b}$ & $98,60 a b$ & $3280,50 \mathrm{~b}$ & $15,27 \mathrm{~b}$ \\
\hline T2 & $16,54 \mathrm{a}$ & $68,75 a b$ & $147,20 \mathrm{a}$ & 4945,55 a & $35,84 a b$ \\
\hline T3 & $16,33 \mathrm{a}$ & 91,25 a & $135,57 \mathrm{a}$ & 4855,89 a & $38,31 \mathrm{a}$ \\
\hline T4 & $13,91 \mathrm{ab}$ & $60,50 a b$ & $69,02 \mathrm{~b}$ & 3389,72 b & $12,09 \mathrm{~b}$ \\
\hline T5 & $15,37 \mathrm{ab}$ & $84,50 a b$ & $135,57 \mathrm{a}$ & $4901,74 \mathrm{a}$ & $26,89 a b$ \\
\hline
\end{tabular}

As médias seguidas de pelo menos uma letra na coluna, não diferem do nível de $5 \%$ de probabilidade, pelo teste Tukey

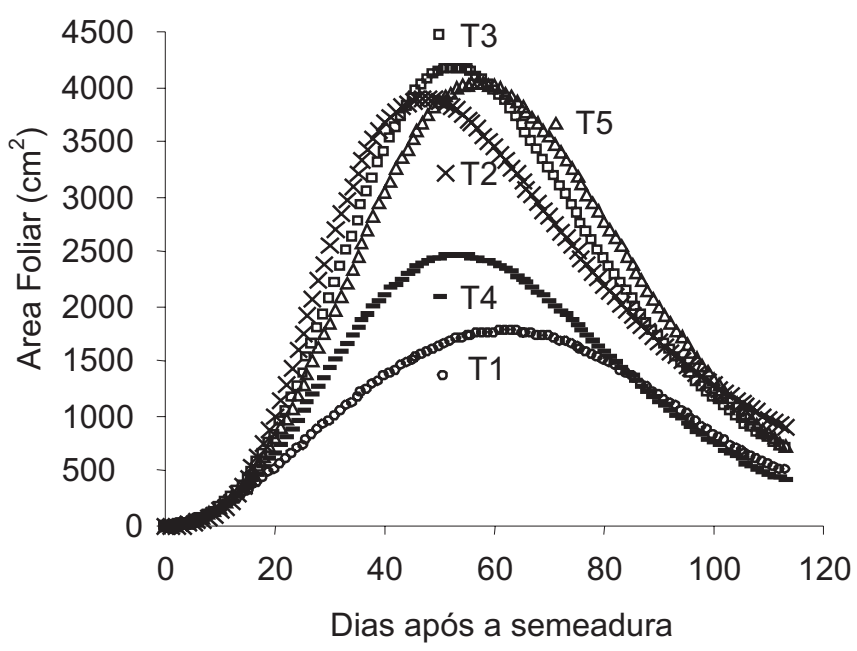

Figura 2. Comportamento da área foliar da cultura do pimentão, nos cinco tratamentos

Observa-se que a área foliar média indicada na Tabela 8, não apresenta diferenças significativas em relação aos tratamentos 1 e 4 ( $p>0,05)$ e, no tratamento 1 (solo sem adubação e água de poço), a menor média, enquanto no tratamento 4 (solo sem adubação e efluente de lagoa de polimento) levemente maior. Também não se observaram diferenças significativas $(p>0,05)$ entre as variáveis dos tratamentos 2, 3 e 5, irrigação com água de poço e solo com adubo orgânico (vermicomposto), solo irrigado com lagoa de polimento e solo irrigado com efluente do reator UASB, respectivamente.

Comparando-se a área foliar dos tratamentos T2 (adubação completa) e T5 (efluente anaeróbio), conforme a Figura 2, a área foliar máxima em T2 foi atingida aos quarenta dias; no entanto, em T5 a área máxima ocorreu aos sessenta dias significando, quanto à utilização de esgotos na agricultura, retardamento do ciclo vegetativo da cultura.

As equações de ajuste das curvas de regressão de variações de área foliar da cultura do pimentão seguiram modelo polinomial, conforme dados descritos na Tabela 9.

\section{Produtividade da cultura do pimentão}

Com exceção dos tratamentos 1 e 4, os demais apresentaram produtividade média dentro da faixa da realidade agrícola nacional, que varia entre 20 e $35 \mathrm{t} \mathrm{ha}^{-1}$, conforme a Tabela 8. 
Tabela 9. Equações de regressão das curvas de variação da área foliar da cultura do pimentão

\begin{tabular}{ccc}
\hline Tratamento & \multicolumn{1}{c}{ Equação } & $\mathbf{R}^{2}$ \\
T1 & $Y=0,0027+0,082 x+1,859 x^{2}-0,030 x^{3}+0,0001 x^{4}$ & 0,996 \\
T2 & $Y=0,0073+0,2190 x+4,918 x^{2}-0,090 x^{3}+0,0004 x^{4}$ & 0,94 \\
T3 & $Y=0,0072+0,2149 x+4,827 x^{2}-0,086 x^{3}+0,0003 x^{4}$ & 0,966 \\
T4 & $Y=0,0044+0,132 x+2,968 x^{2}-0,052 x^{3}+0,0002 x^{4}$ & 0,987 \\
T5 & $Y=0,0065+0,193 x+4,338 x^{2}-0,074 x^{3}+0,0003 x^{4}$ & 0,979 \\
\hline
\end{tabular}

A baixa produtividade verificada no tratamento 4 se deve, provavelmente, à alta concentração hidrogeniônica presente no efluente de lagoa de polimento. Para o pimentão, o pH ótimo do solo se situa entre 5,5 a 7,0 (Doorenbos \& Kassan, 1994). O pH influencia a solubilidade dos elementos químicos do solo, enquanto o fator limitante em relação à disponibilidade de nutrientes para a planta, pode ser a presença de matéria orgânica, óxido de ferro, alumínio, manganês e sais de cálcio.

Os cátions, ferro, manganês, zinco, cobre e cobalto, são micronutrientes poucos assimilados pelas plantas, quando a fertirrigação ocorre em $\mathrm{pH}$ elevado, mais que 8 unidades. Neste contexto, o nitrogênio, o fósforo, o enxofre e o boro têm suas disponibilidades consideravelmente reduzidas (Malavolta, 1976; Marques et al., 2003).

A mudança do $\mathrm{pH}$ do solo devido à água de irrigação, ocorre de forma muito lenta (Ayers \& Westcot, 1991). No caso do tratamento 4, o efluente de lagoa de polimento se manteve com pH em torno de 9; desta forma, os íons fosfatos poderão reagir rapidamente para formar compostos pouco solúveis, comprometendo a assimilação de fósforo pela planta (Brady, 1989; Malavolta, 1976).

\section{CONCLUSÕES}

1. O efluente da lagoa de polimento com $\mathrm{pH}$ variando entre 8,5 e 9,8 nas condições do experimento, não disponibilizou nutrientes suficientes para o bom desempenho da cultura do pimentão.

2. As parcelas irrigadas por efluente do reator UASB, irrigação com água de poço artesiano em solo com adubação orgânica e a mesma irrigação em solo com vermicomposto, apresentaram resultados similares quanto à área foliar e ao peso médio dos frutos.

3. O valor fertilizante dos nutrientes em águas residuárias é, de modo geral, considerado benéfico.

4. Substitui a fertilidade natural do solo e/ou a aplicação de adubos, quando estes são insuficientes para manter as necessidades nutricionais das plantas, por muito tempo.

5. A fitomassa, a área foliar e a produtividade nos tratamentos com adubação completa, adubação orgânica com vermicomposto e irrigação com efluente do reator UASB, não apresentaram estatisticamente, diferença significativa.

6. O efluente anaeróbio apresenta-se como alternativa para reúso, do ponto de vista nutricional.

\section{AGRADECIMENTOS}

Os autores agradecem ao CT-Hidro, ao CNPq, BNB, à Companhia de Águas e Esgotos da Paraíba - CAGEPA, a EXTRABES e ao Programa de Pesquisa em Saneamento Básico - PROSAB.

\section{LITERATURA CITADA}

ANVISA - Agência Nacional de Vigilância Sanitária. ResoluçãoRDC n.12, de 2 de janeiro de 2001.

APHA. AWWA. WPCF. Standard methods for the examination of water and wastewater. 15 ed. Washington: D. American Public Health Association. American Water Works Association, Water Pollution Control Federation, 1995, 1134p.

Ayers, R. S.; Westcoot, D. W. A qualidade de água na agricultura. Campina Grande: UFPB, 1991, 218p.

Bailenger, J. Mechanisms of parasitological concentration in coprology and their practical consequences. Journal of American medical technology, 41, apud Ayres, R. Mara, D. Analysis of wastewater for use in agriculture. A laboratory manual of parasitological and bacteriological techniques. Geneva: WHO, 1989, p.65-71

Bastos, R. K. X.; Mara, D. D. The bacterial quality of salad crop drip and furrow irrigated with waste stabilization pond effluent: an evaluation of the WHO guidelines. Water Science and Technology. London. v.31, n.12, p.425-430, 1995.

Brady, M. C. Natureza e propriedades do solos. 7. ed. Rio de Janeiro: Livraria Freitas Bastos, 1989. 878p.

Cavalcanti, P. F. F. Integrated application of the UASB reactor and ponds for domestic sewage treatment in tropical regions. The Netherlands: Wageningen University, 2003. 139p. Thesis PhD

Cavalcanti, P. F. F.; van Haandel, A. C.; Lettinga, G. Polishing ponds for post treatment of digested sewage. Sequential batch ponds. In: Oficina Seminário Latino-Americano de digestão anaeróbia. Recife, Anais... Recife: 2000. p.352-359

Doorenbos, J.; Kassam, A. H. Efeito da água no rendimento das culturas. Campina Grande: UFPB, 1994.306p.

EMBRAPA - Empresa Brasileira de Pesquisa Agropecuária. Manual de métodos de análise de solo, Rio de Janeiro: Serviço Nacional de Levantamento e Conservação do Solo: SNLCS, 1979. (n.p)

Holanda, J. S. de; Amorim, J. R. A. de. Qualidade da água para irrigação In.: Gheyi, H. R.; Queiroz, J. E.; Medeiros, J. F. (ed.) Manejo e controle da salinidade na cultura irrigada. Campina Grande: UFPB/SBEA, 1997. p.137-169.

Kellner, E.; Pires, E. C. Lagoas de estabilização: projeto e operação. Rio de Janeiro: ABES, 1998. 244p.

Magalhães, W. S.; Campos R. T. Economia agrícola, recursos naturais e meio ambiente. Revista Econômica do Nordeste, Fortaleza, v.28, n.especial, p.417-429, 1997.

Malavolta, E. Manual de química agrícola: Nutrição de plantas e fertilidade do solo. São Paulo: Agronômica Ceres, 1976. 528p.

Malavolta, E. Métodos para la determinación de deficiencia. In: Fitopatologia - Curso moderno, Tomo IV. Ed. Por Sarasola A. A. e Sarasola M. A. R. Buenos Aires: Editorial Hemisfério Sur. 1965. p.244-247.

R. Bras. Eng. Agríc. Ambiental, v.10, n.1, p.89-96, 2006. 
Marques, M. O.; Coraucci Filho, B.; Bastos, R. K. X.; Kato, M. T.; Lima, V. L. A. de; Andrade Neto, C. O.; Mendonça, F. C.; Marques, P. A. A.; Marques, T. A.; Bellingieri, P. H.; van Haandel, A. C. Uso de esgotos tratados em irrigação: Aspectos agronômicos e ambientais. In: Bastos, R. K. X. Utilização de esgotos tratados em fertirrigação, hidroponia e piscicultura. Rio de Janeiro: ABES, RiMa, 2003. p.61-118.

Metcalf \& Eddy. Inc. Wastewater engineering treatment disposal reuse. 3.ed. NewYork: McGraw - Hill Book, 1991. 1334p.

Paganini, W. S. Reúso de água na agricultura. In: Mancuso, P. S. S.; Santos, H. F. (ed) Reúso de água. Barueri: Manole, 2003. p.338-401.

Primavesi, A. Agricultura em regiões tropicais. Manejo ecológico do solo. São Paulo: Nobel. 2002. 549p.

Queiroz, J. E.; Gonçalves, A. C.; Souto, J. S.; Folegatti, M. V. Avaliação e monitoramento à salinidade do solo. In.: Gheyi, H. R.; Queiroz, J. E.; Medeiros, J. F. (ed.) Manejo e controle da salinidade na cultura irrigada. Campina Grande: UFPB/SBEA, 1997. p.69-111.

Shuval, H.; Lampert Y.; Fattal, B. Development of a risk assessment approach for evaluating wastewater reuse standards for agriculture. Water Science and Technology, Oxford. v.35, n.11-12, p.15-20, 1997.
Shuval, H. I.; Adin, A.; Fal, B.; Rawitz, E.; Yekutiel, P. Wastewater irrigation in developing countries health effects and technical solutions. World Bank Technical Paper Number 51, Integrated Resource Recovery Projects series number GLO/80/004, Washington, D.C. 1986, 324p.

Silva, S. A.; Mara, D. D. Tratamentos biológicos de águas residuárias: lagoas de estabilização. Rio de janeiro: ABES, 1979.140p.

Sousa, J. T. de; Leite, V. D. Tratamento e utilização de esgotos domésticos na agricultura. Campina Grande: EDUEP, 2003. 135p.

Tedesco, M. J.; Gianello, C.; Bissani, C. A.; Bohnen, H.; Volkweiss, S. J. Análise de solo, plantas e outros materiais. Porto Alegre. Departamento de Solos; Faculdade de Agronomia, UFRGS. 1995. 174p. Boletim Técnico, n.5.

van Haandel, A. C.; Lettinga, G. Tratamento anaeróbio de esgotos: um manual para regiões de clima quente. 1994.

von Sperling, M. Princípios de tratamento biológico de águas residuárias: lagoas de estabilização. 3.ed. Belo Horizonte: Departamento de Engenharia Sanitária e Ambiental/UFMG, 2002. v.3, 196p.

WHO - World Health Organization. Health guidelines for the use of wastewater in agriculture and aquaculture. Tecnical Report Series. 778. Geneva: World Health and Organization, 1989. 74p. 